\title{
Efficacy and safety of combination of magnesium sulfate, phentolamine and nifedipine in treatment of patients with hypertensive disorder complicating pregnancy
}

\author{
JINGGUI ZHANG ${ }^{1}$ and JUN LI ${ }^{2}$ \\ ${ }^{1}$ Department of Cardiovascular Medicine, Affiliated Hospital of Beihua University, Jilin 132001; \\ ${ }^{2}$ Screening Laboratory, Jilin Hospital for Gynecology and Obstetrics, Jilin 132011, P.R. China \\ Received May 6, 2019; Accepted July 1, 2019
}

DOI: $10.3892 /$ etm.2019.7965

\begin{abstract}
Efficacy and safety of the combination of magnesium sulfate, phentolamine and nifedipine in the treatment of patients with hypertensive disorder complicating pregnancy (HDCP) and its effect on hemodynamics and urinary protein level were investigated. One hundred and six patients with HDCP diagnosed at the Affiliated Hospital of Beihua University from February 5, 2016 to May 9, 2017 were retrospectively analyzed. Patients were divided into the magnesium sulfate group and the combination group, according to the therapeutic schemes. The efficacy 1 week later was observed. The general clinical data of the patients were recorded, and data were acquired with respect to hemodynamic indexes before and after treatment [changes of $\mathrm{S} / \mathrm{D}$ ratio of umbilical artery flow, and cardiac index and total peripheral resistance (TPR)], the 24-h urinary protein level, clinical efficacy and safety [adverse drug reactions (ADR) and maternal and neonatal outcomes]. Before treatment, there was no statistically significant difference between the two groups in terms of $S / D$ ratio of umbilical artery flow $(P>0.05)$, while after treatment the $\mathrm{S} / \mathrm{D}$ ratio was significantly lower than that before treatment in both groups $(\mathrm{P}<0.05)$. Before treatment, there was no statistically significant difference between the two groups in terms of cardiac index $(\mathrm{P}>0.05)$. TPR after treatment was significantly lower than that before treatment in both groups $(\mathrm{P}<0.001)$. Compared with the magnesium sulfate group, patients in the combination group had significantly lower 24-h urinary protein level after treatment $(\mathrm{P}<0.001)$, significantly higher total effective rate $(\mathrm{P}<0.05)$, significantly lower incidence rate of ADR $(\mathrm{P}<0.001)$, and significantly lower incidence rate of adverse maternal and neonatal outcomes $(\mathrm{P}<0.001)$. In conclusion, the combination of magnesium
\end{abstract}

Correspondence to: Dr Jun Li, Screening Laboratory, Jilin Hospital for Gynecology and Obstetrics, 53 Guanghua Road, Jilin 132011, P.R. China

E-mail: vsujs7@163.com; 50414587@qq.com

Key words: magnesium sulfate, phentolamine, nifedipine, hypertensive disorder complicating pregnancy, hemodynamics, urinary protein sulfate, phentolamine and nifedipine can significantly improve the hemodynamic indexes, the 24-h urinary protein level, the clinical efficacy, ADR and maternal and neonatal outcomes of patients with HDCP, therefore it is worthy of use in the clinic.

\section{Introduction}

Hypertensive disorder complicating pregnancy (HDCP), a common condition with a high incidence rate in the Obstetrics and Gynecology Department, usually occurs after 20 weeks of gestation $(1,2)$. With the changes of the social environment in recent years, the incidence rate of the disease has been increasing year by year due to unhealthy living habits and dietary structure $(3,4)$. Severe HDCP poses a threat to maternal and child health which can lead to massive intra-abdominal hemorrhage and patient death (4).

As an anticonvulsant, magnesium sulfate is currently the first choice for the prevention and treatment of HDCP (5). It inhibits the dilatation of peripheral vessels through central inhibition, and indirectly reduces blood pressure by relieving vasospasm $(6,7)$. However, although magnesium sulfate is clinically effective in the treatment of HDCP, it has a slow effect and its therapeutic dose greatly influences the patients' blood concentration $(8,9)$. According to recent studies, nifedipine, a long-acting calcium antagonist, inhibits angiotensin converting enzymes and significantly lowers blood pressure, and its safety is better than that of antihypertensive drugs of the same type $(10,11)$. Phentolamine, a blocker that is mainly used for treating peripheral vascular diseases (12), blocks norepinephrine, increases myocardial contractility and reduces the related resistance of peripheral vessels, effectively dilating blood vessels (13). Antihypertensive drugs are effective on HDCP patients, but there is no conclusion as to which therapeutic regimen is the most effective. Therefore, the efficacy and safety of the combination of magnesium sulfate, phentolamine and nifedipine in the treatment of HDCP patients and its effect on hemodynamics and urinary protein level were investigated in this study.

\section{Patients and methods}

General information. One hundred and six patients with HDCP diagnosed at the Affiliated Hospital of Beihua 
Table I. General clinical data [n (\%)].

\begin{tabular}{|c|c|c|c|c|}
\hline Groups & $\begin{array}{l}\text { Combination } \\
\text { group }(n=53)\end{array}$ & $\begin{array}{l}\text { Magnesium sulfate } \\
\text { group }(n=53)\end{array}$ & $\mathrm{t} / \chi^{2}$ value & P-value \\
\hline Age (years) & $26.48 \pm 6.93$ & $26.53 \pm 7.03$ & 0.037 & 0.971 \\
\hline Body mass index $\left(\mathrm{kg} / \mathrm{m}^{2}\right)$ & $18.47 \pm 3.14$ & $18.68 \pm 2.41$ & 0.386 & 0.700 \\
\hline Gestational age (weeks) & $34.56 \pm 4.68$ & $34.32 \pm 4.59$ & 0.267 & 0.790 \\
\hline Pregnancy history & & & 0.050 & 0.824 \\
\hline Primipara & $40(75.47)$ & $39(73.58)$ & & \\
\hline Multipara & $13(24.53)$ & $14(26.42)$ & & \\
\hline Excessive nutritional supplement & & & 0.632 & 0.230 \\
\hline Yes & $41(77.36)$ & $43(81.13)$ & & \\
\hline No & $12(22.64)$ & $10(18.86)$ & & \\
\hline History of preeclampsia & & & 0.376 & 0.540 \\
\hline Yes & $5(9.43)$ & $7(13.21)$ & & \\
\hline No & $48(90.57)$ & $46(86.79)$ & & \\
\hline History of chronic nephritis & & & 0.050 & 0.824 \\
\hline Yes & $13(24.53)$ & $14(26.42)$ & & \\
\hline No & $40(75.47)$ & $39(73.58)$ & & \\
\hline Hypertension & & & 0.099 & 0.952 \\
\hline Mild & $23(43.40)$ & $23(43.40)$ & & \\
\hline Moderate & $15(28.30)$ & $16(30.19)$ & & \\
\hline Severe & $15(28.30)$ & $14(26.42)$ & & \\
\hline
\end{tabular}

University (Jilin, China) from February 5, 2016 to May 9, 2017 were retrospectively analyzed, and divided into the magnesium sulfate group $(\mathrm{n}=53)$ and the combination group $(\mathrm{n}=53)$ according to the therapeutic schemes. Patients in the combination group, were treated with magnesium sulfate, phentolamine and nifedipine, and were 22-40 years of age with an average age of $26.48 \pm 6.93$ years. Patients in the magnesium sulfate group were treated with magnesium sulfate alone, and were 22-38 years of age with an average age of $26.53 \pm 7.03$ years. Inclusion criteria: patients with HDCP only treated in the Affiliated Hospital of Beihua University; those who had no abortion caused by abnormal chromosome; with no endocrine abnormality, any reproductive system infection or autoimmune disease (14). Exclusion criteria: patients with hypertension, hepatitis B virus, gallstones, AIDS and blood diseases were excluded, as well as pregnant women with abnormal pregnancy history. Patients included had complete clinical data. The study was approved by the Ethics Committee of the Affiliated Hospital of Beihua University. Patients and their families signed an informed consent form in advance.

Therapeutic regimens. Patients in the magnesium sulfate group were treated with magnesium sulfate alone (Hebei Tiancheng Pharmaceutical Co., Ltd.; SFDA approval no. H20033861). The patients received an intravenous drip with $100 \mathrm{ml}$ of 5\% glucose solution (Newland Pharmaceutical Co., Ltd.; SFDA approval no. H20065564) rapidly for $30 \mathrm{~min}$, and then $40 \mathrm{ml}$ of $25 \%$ magnesium sulfate for 6-8 $\mathrm{h}$, that was dissolved in $500 \mathrm{ml}$ of $5 \%$ glucose. Patients in the combination group were treated with phentolamine (Shanghai Xudong Haipu
Pharmaceutical Co., Ltd.; SFDA approval no. H31020589) on the basis of the magnesium sulfate group. The patients received an intravenous drip with $20 \mathrm{mg}$ of phentolamine, that was dissolved in $200 \mathrm{ml}$ of $5 \%$ glucose, and then $20 \mathrm{mg}$ of nifedipine (Guangdong Xinfeng Pharmaceutical Co., Ltd.; SFDA approval no. H44021999) were orally administered once daily. Both groups of patients were treated for 1 week.

Observational indexes. The general clinical data of patients in the two groups were recorded, and data were acquired with respect to hemodynamic indexes before and after treatment [changes of S/D ratio of umbilical artery flow, cardiac index and total peripheral resistance (TPR)], the 24-h urinary protein level, clinical efficacy and safety [adverse drug reactions (ADR) and maternal and neonatal outcomes]. Markedly effective: patients with HDCP that had normal clinical symptoms and signs, and significantly reduced blood pressure, without HDCP-related complications; systolic blood pressure was reduced by $\geq 30 \mathrm{mmHg}$, diastolic blood pressure by $\geq 20 \mathrm{mmHg}$, urinary protein by $\geq 20 \mathrm{mg}$. Effective: the clinical symptoms and signs were significantly improved with less complications; blood pressure was reduced by $\leq 10 \mathrm{mmHg}$, urine protein by $\leq 20 \mathrm{mg}$. Invalid: the clinical symptoms and signs were unchanged and blood pressure was not reduced, with more complications (4). Total effective rate $=$ (markedly effective + effective)/total cases $\mathrm{x} 100 \%$.

Statistical analysis. SPSS 19.0 software [Bizinsight (Beijing) Information Technology Co., Ltd.] was used for statistical analysis. Count data were expressed as the number 


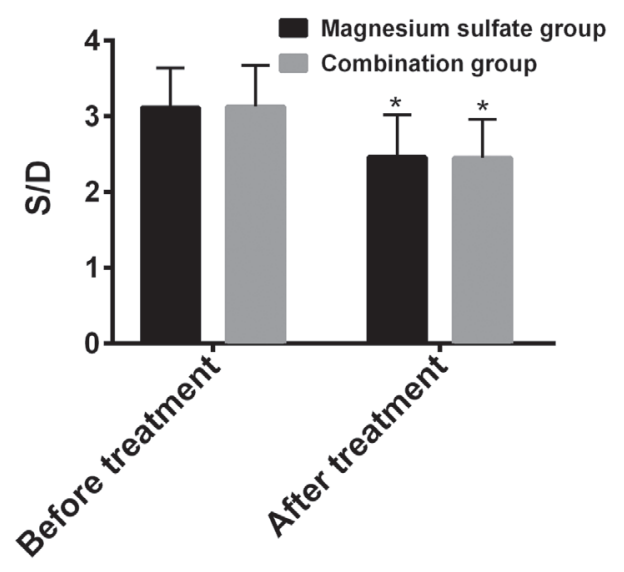

Figure 1. Changes of S/D ratio of umbilical artery flow. The S/D ratio of umbilical artery flow after treatment was significantly lower than that before treatment in both groups $\left({ }^{*} \mathrm{P}<0.05\right)$.

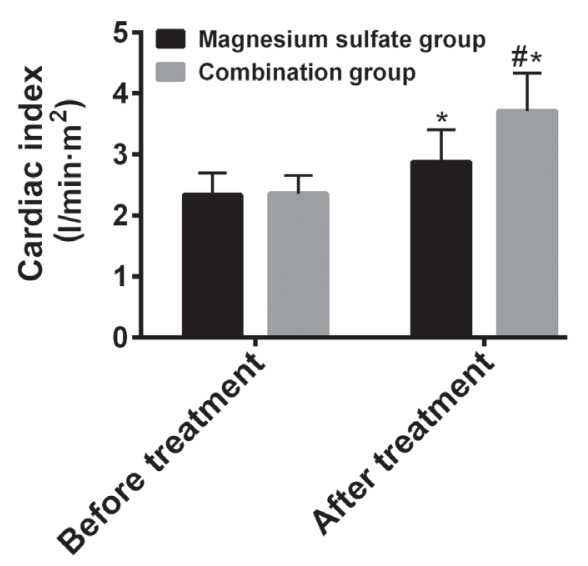

Figure 2. Changes of cardiac index. The cardiac index after treatment was significantly higher than that before treatment in both groups $\left({ }^{*} \mathrm{P}<0.05\right)$ and cardiac index after treatment was significantly higher in the combination group than that in the magnesium sulfate group $\left({ }^{\#} \mathrm{P}<0.05\right)$.

of cases and percentage [n (\%)], and were tested by $\chi^{2}$ test. Measurement data were expressed as the mean \pm standard deviation (mean $\pm \mathrm{SD}$ ), and t-test was used for comparisons between two groups, while one-way ANOVA, with Least Significant Difference post hoc test, for comparisons of multiple groups. $\mathrm{P}<0.05$ was considered to indicate a statistically significant difference.

\section{Results}

General clinical data. There was no statistically significant difference between the two groups in general data $(P>0.05)$. The two groups of patients were comparable. Details are shown in Table I.

\section{Changes of hemodynamic indexes}

i) Changes of $S / D$ ratio of umbilical artery flow. The S/D ratios of umbilical artery flow before and after treatment were respectively $3.12 \pm 0.52$ and $2.46 \pm 0.56$ in the magnesium sulfate group, $3.13 \pm 0.54$ and $2.45 \pm 0.51$ in the combination group (Fig. 1). Before treatment, there was no statistically significant difference between the two groups in terms of

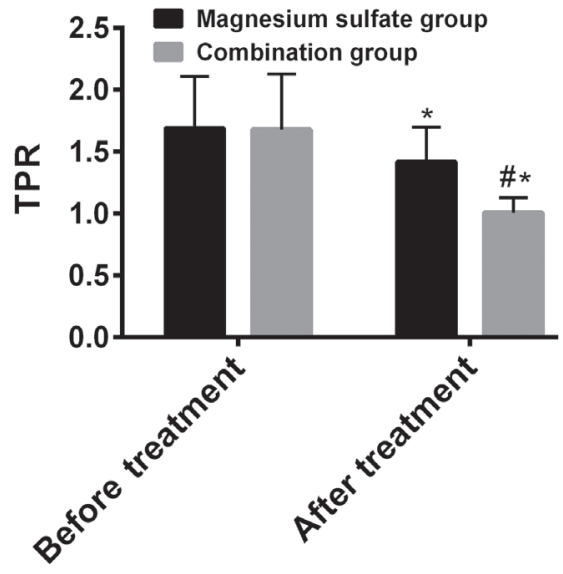

Figure 3. Changes of TPR. TPR after treatment was significantly lower than that before treatment in both groups $(" \mathrm{P}<0.001)$ and TPR after treatment was significantly lower in the combination group than that in the magnesium sulfate group $\left({ }^{*} \mathrm{P}<0.001\right)$. TPR, total peripheral resistance.

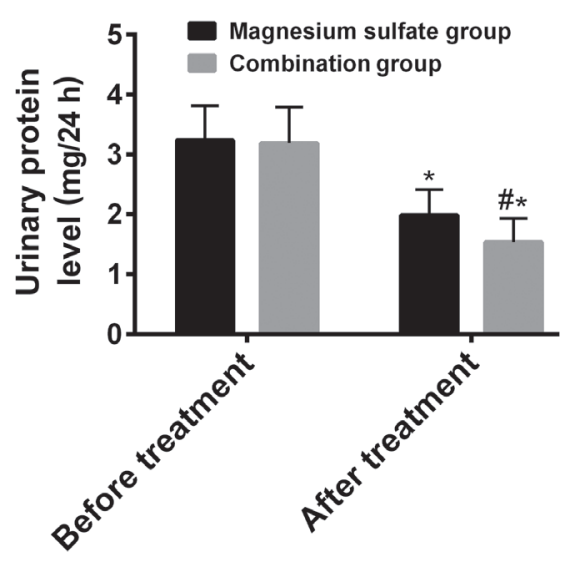

Figure 4. Changes of urinary protein level. The 24-h urinary protein level after treatment was significantly lower than that before treatment in both groups ( $\left.{ }^{*} \mathrm{P}<0.001\right)$ and the 24 -h urinary protein level after treatment was significantly lower in the combination group than that in the magnesium sulfate group $\left({ }^{\#} \mathrm{P}<0.001\right)$.

S/D ratio of umbilical artery flow $(\mathrm{P}>0.05)$. After treatment the $S / D$ ratio was significantly lower than that before treatment in both groups $(\mathrm{P}<0.05)$, and there was no statistically significant difference between the two groups $(\mathrm{P}>0.05)$ (Fig. 1).

ii) Changes of cardiac index. The cardiac indexes before and after treatment were respectively $2.34 \pm 0.36$ and $2.88 \pm 0.53 \mathrm{l} / \mathrm{min} \cdot \mathrm{m}^{2}$ in the magnesium sulfate group, $2.36 \pm 0.30$ and $3.71 \pm 0.62 \mathrm{l} / \mathrm{min} \cdot \mathrm{m}^{2}$ in the combination group (Fig. 2). Before treatment, there was no statistically significant difference between the two groups in terms of cardiac index $(P>0.05)$. After treatment the cardiac index was significantly higher than that before treatment in both groups $(\mathrm{P}<0.05)$, and it was significantly higher in the combination group than that in the magnesium sulfate group $(\mathrm{P}<0.05)$ (Fig. 2).

iii) Changes of TPR. TPR before and after treatment was respectively $1.69 \pm 0.42$ and $1.42 \pm 0.28$ in the magnesium sulfate group, $1.68 \pm 0.45$ and $1.01 \pm 0.12$ in the combination group (Fig. 3). Before treatment, there was no statistically significant difference between the two groups in terms of TPR $(P>0.05)$. After treatment TPR was significantly lower than 
Table II. Efficacy observation [n (\%)].

\begin{tabular}{lccccc}
\hline Groups & $\mathrm{n}$ & Markedly effective & Effective & Invalid & Total effective rate \\
\hline Magnesium sulfate group & 53 & $24(45.28)$ & $20(37.74)$ & $9(16.98)$ & $44(83.02)$ \\
Combination group & 53 & $31(58.49)$ & $20(37.74)$ & $2(3.77)$ & $51(96.23)$ \\
$\chi^{2}$ value & - & - & - & - & 4.970 \\
P-value & - & - & - & - & 0.026 \\
\hline
\end{tabular}

Table III. Comparison of ADR [n (\%)].

\begin{tabular}{lccccccc}
\hline Groups & Vomiting & Diarrhea & Fever & Weakness & Headache & Rash & Total \\
\hline Magnesium sulfate group & $9(16.98)$ & $3(5.66)$ & $6(11.32)$ & $10(18.87)$ & $7(13.21)$ & $2(3.77)$ & $37(69.81)$ \\
Combination group & $1(1.89)$ & $1(1.89)$ & $3(5.66)$ & $9(16.98)$ & $5(9.43)$ & $0(0.00)$ & $19(35.85)$ \\
$\chi^{2}$ value & - & - & - & - & - & - & 12.270 \\
P-value & - & - & - & - & - & - & $<0.001$ \\
\hline
\end{tabular}

ADR, adverse drug reactions.

Table IV. Comparison of maternal and neonatal outcomes [n (\%)].

\begin{tabular}{lcccccc}
\hline Groups & $\begin{array}{c}\text { Premature } \\
\text { delivery }\end{array}$ & $\begin{array}{c}\text { Caesarean } \\
\text { delivery }\end{array}$ & $\begin{array}{c}\text { Postpartum } \\
\text { hemorrhage }\end{array}$ & $\begin{array}{c}\text { Neonatal } \\
\text { asphyxia }\end{array}$ & $\begin{array}{c}\text { Perinatal } \\
\text { death }\end{array}$ & Total \\
\hline Magnesium sulfate group & $8(15.09)$ & $12(22.64)$ & $7(13.21)$ & $7(13.21)$ & $1(1.89)$ & $35(66.04)$ \\
Combination group & $1(1.89)$ & $10(18.87)$ & $2(3.77)$ & $2(3.77)$ & $0(0.00)$ & $15(28.30)$ \\
$\chi^{2}$ value & - & - & - & - & - & 15.140 \\
P-value & - & - & - & - & - & $<0.001$ \\
\hline
\end{tabular}

that before treatment in both groups $(\mathrm{P}<0.001)$, and it was significantly lower in the combination group than that in the magnesium sulfate group $(\mathrm{P}<0.001)$ (Fig. 3).

Changes of urinary protein level. The 24-h urinary protein levels before and after treatment were respectively $3.24 \pm 0.58$ and $1.99 \pm 0.43 \mathrm{mg} / 24 \mathrm{~h}$ in the magnesium sulfate group, $3.19 \pm 0.60$ and $1.54 \pm 0.39 \mathrm{mg} / 24 \mathrm{~h}$ in the combination group (Fig. 4). Before treatment, there was no statistically significant difference between the two groups in terms of 24-h urinary protein level $(\mathrm{P}>0.05)$. After treatment the urinary protein level was significantly lower than that before treatment in both groups $(\mathrm{P}<0.001)$, and it was significantly lower in the combination group than that in the magnesium sulfate group $(\mathrm{P}<0.001)$ (Fig. 4).

Efficacy observation. In the magnesium sulfate group, the treatment was markedly effective in 24 patients, effective in 20 patients, and invalid in 9 patients, with a total effective rate of $83.02 \%$. In the combination group, the treatment was markedly effective in 31 patients, effective in 20 patients, and invalid in 2 patients, with a total effective rate of $96.23 \%$. The total effective rate in the combination group was significantly higher than that in the magnesium sulfate group $(\mathrm{P}<0.05)$ (Table II).
Safety observation

i) Comparison of $A D R$. The total number of patients with vomiting, diarrhea, fever, weakness, headache and rash was 37 in the magnesium sulfate group and 19 in the combination group. The incidence rate of ADR in the combination group was significantly lower than that in the magnesium sulfate group $(\mathrm{P}<0.001)$ (Table III).

ii) Comparison of maternal and neonatal outcomes. The total number of patients with premature delivery, caesarean delivery, postpartum hemorrhage, neonatal asphyxia and perinatal death was 35 in the magnesium sulfate group and 15 in the combination group. The incidence rate of adverse maternal and neonatal outcomes in the combination group was significantly lower than that in the magnesium sulfate group $(\mathrm{P}<0.001)$ (Table IV).

\section{Discussion}

The general clinical data of patients in this study revealed that the two groups of patients were comparable. Hemodynamic indexes before and after treatment, the 24-h urinary protein level, clinical efficacy and safety of therapeutic regimens were observed. The S/D ratio of umbilical artery flow after treatment was significantly lower than that before treatment 
in the both groups, whereas there was no statistically significant difference between the two groups after treatment. According to relevant studies, the $\mathrm{S} / \mathrm{D}$ ratio of umbilical artery flow is helpful to determine the intrauterine growth of fetus, and reflects whether a pregnant woman has HDCP or whether the fetus has the tendency of intrauterine hypoxia and developmental retardation $(15,16)$. It gradually stabilizes with the increase of gestational age, and its increase caused by HDCP leads to fetal anoxia and even brain tissue injury (17). Therefore, it is believed that the two therapeutic schemes in this study reduce the $S / D$ ratio of umbilical artery flow, with similar effects on the ratio. In this study, TPR after treatment was significantly lower than that before treatment in the two groups, which after treatment was significantly lower in the combination group than that in the magnesium sulfate group. Cardiac index after treatment was significantly higher than that before treatment in both groups, and after treatment it was significantly higher in the combination group than that in the magnesium sulfate group. Changes of TPR and cardiac index are common hemodynamic indexes for observing patients with HDCP (18). The pathological changes of blood vessels caused by HDCP result in small blood vessel spasm, vascular stenosis and increased peripheral resistance, as well as decreased cardiac index in pregnant women (19). Therefore, it is believed that the combination of magnesium sulfate, phentolamine and nifedipine is better than magnesium sulfate alone in improving the hemodynamic indexes of patients with HDCP. In a study by Adamo et al, magnesium sulfate combined with other antihypertensive drugs was shown to be better than magnesium sulfate alone in this improvement (20). In this study, the 24-h urinary protein level after treatment was significantly lower than that before treatment in the two groups, and after treatment was significantly lower in the combination group than that in the magnesium sulfate group. Also, the total effective rate in the combination group was significantly higher than that in the magnesium sulfate group. High blood pressure and increased urine protein are the most direct clinical features of HDCP in pregnant women, which are caused by kidney damage as a result of hypertension. According to a relevant study, the 24-h urine protein level is a monitoring index for patients with HDCP (21), the effective downregulation of which indicates improvement of the condition (22). In this study, the incidence rate of adverse maternal and neonatal outcomes (premature delivery, caesarean delivery, postpartum hemorrhage, neonatal asphyxia and perinatal death) in the combination group were significantly lower than that in the magnesium sulfate group. A large number of studies on the treatment of HDCP have confirmed that magnesium sulfate combined with other antihypertensive drugs is more effective in preventing ADR of patients with HDCP and improving maternal and neonatal outcomes (23-25).

The regional limitations of the patients included and the lack of rich monitoring indexes may have affected the statistical results. Therefore, further research on the patients included and valuable monitoring indexes for HDCP will be appropriately added in our future studies.

In summary, the combination of magnesium sulfate, phentolamine and nifedipine can significantly improve the hemodynamic indexes, the 24-h urinary protein level, clinical efficacy, ADR and maternal and neonatal outcomes of patients with HDCP.

\section{Acknowledgements}

Not applicable.

\section{Funding}

No funding was received.

\section{Availability of data and materials}

The datasets used and/or analyzed during the present study are available from the corresponding author on reasonable request.

\section{Authors' contributions}

JZ interpreted the data, drafted the manuscript, conceived and designed the study. JL collected and analyzed the data, and finally revised the manuscript. Both authors read and approved the final manuscript.

\section{Ethics approval and consent to participate}

The study was approved by the Ethics Committee of the Affiliated Hospital of Beihua University (Jilin, China). Patients who participated in this research had complete clinical data. The patients and their families signed an informed consent form in advance.

\section{Patient consent for publication}

Not applicable.

\section{Competing interests}

The authors declare that they have no competing interests.

\section{References}

1. Barakat R, Pelaez M, Cordero Y, Perales M, Lopez C, Coteron J and Mottola MF; Randomized Clinical Trial: Exercise during pregnancy protects against hypertension and macrosomia: Randomized clinical trial. Am J Obstet Gynecol 214: 649.e1-649.e8, 2016.

2. Liu FM, Zhao M, Wang M, Yang HL and Li L: Effect of regular oral intake of aspirin during pregnancy on pregnancy outcome of high-risk pregnancy-induced hypertension syndrome patients. Eur Rev Med Pharmacol Sci 20: 5013-5016, 2016.

3. Madsen C, Håberg SE, Aamodt G, Stigum H, Magnus P, London SJ, Nystad W and Nafstad P: Preeclampsia and hypertension during pregnancy in areas with relatively low levels of traffic air pollution. Matern Child Health J 22: 512-519, 2018.

4. Johnson P, Montgomery M and Ewell P: Elevated blood pressure in low-income, rural preschool children is associated with maternal hypertension during pregnancy. J Community Health Nurs 35: 12-18, 2018.

5. Maged AM, Hashem AM, Gad Allah SH, Mahy ME, Mostafa WA and Kotb A: The effect of loading dose of magnesium sulfate on uterine, umbilical, and fetal middle cerebral arteries Doppler in women with severe preeclampsia: A case control study. Hypertens Pregnancy 35: 91-99, 2016.

6. Niwa K: Adult congenital heart disease with pregnancy. Korean Circ J 48: 251-276, 2018. 
7. Brookfield KF, Su F, Elkomy MH, Drover DR, Lyell DJ and Carvalho B: Pharmacokinetics and placental transfer of magnesium sulfate in pregnant women. Am J Obstet Gynecol 214: 737.e1-737.e9, 2016.

8. Cho CK, Sung TY, Choi SJ, Choi HR, Kim YB, Lee JU and Yang HS: The effect of magnesium sulfate concentration on the effective concentration of rocuronium, and sugammadex-mediated reversal, in isolated left phrenic nerve hemi-diaphragm preparations from the rat. Korean J Anesthesiol 71: 401-406, 2018

9. Sarma AK, Khandker N, Kurczewski L and Brophy GM: Medical management of epileptic seizures: Challenges and solutions. Neuropsychiatr Dis Treat 12: 467-485, 2016.

10. Park JB, Shin JH, Kim DS, Youn HJ, Park SW, Shim WJ, Park CG, Kim DW, Lee HY, Choi DJ, et al; FOCUS Investigators: Safety of the up-titration of nifedipine GITS and valsartan or low-dose combination in uncontrolled hypertension: The FOCUS Study. Clin Ther 38: 832-842, 2016.

11. Webster LM, Myers JE, Nelson-Piercy C, Harding K, Cruickshank JK, Watt-Coote I, Khalil A, Wiesender C, Seed PT and Chappell LC: Labetalol versus Nifedipine as antihypertensive treatment for chronic hypertension in pregnancy: A randomized controlled trial. Hypertension 70: 915-922, 2017.

12. Jin J, Shen X, Tai Y, Li S, Liu M, Zhen C, Xuan X, Zhang X, $\mathrm{Hu} \mathrm{N}$, Zhang X, et al: Arterial relaxation is coupled to inhibition of mitochondrial fission in arterial smooth muscle cells: Comparison of vasorelaxant effects of verapamil and phentolamine. Acta Pharm Sin B 7: 319-325, 2017.

13. Yan Z, Shang Y, Li F, Xie F, Qian H, Zhang Y and Yue B: Therapeutic efficacy of phentolamine in the management of severe hand, foot and mouth disease combined with pulmonary edema. Exp Ther Med 13: 1403-1407, 2017.

14. Schausberger CE, Jacobs VR, Bogner G, Wolfrum-Ristau P and Fischer T: Hypertensive disorders of pregnancy - a life-long risk?! Geburtshilfe Frauenheilkd 73: 47-52, 2013.

15. Hromadnikova I, Kotlabova K, Ivankova K, Vedmetskaya Y and Krofta L: Profiling of cardiovascular and cerebrovascular disease associated microRNA expression in umbilical cord blood in gestational hypertension, preeclampsia and fetal growth restriction. Int J Cardiol 249: 402-409, 2017.

16. Petrakos G, Andriopoulos P and Tsironi M: Pregnancy in women with thalassemia: Challenges and solutions. Int J Womens Health 8: 441-451, 2016.

17. Flo K, Blix ES, Husebekk A, Thommessen A, Uhre AT, Wilsgaard T, Vårtun $\AA$ and Acharya G: A longitudinal study of maternal endothelial function, inflammatory response and uterine artery blood flow during the second half of pregnancy. Acta Obstet Gynecol Scand 95: 225-232, 2016.
18. Guy GP, Ling HZ, Garcia P, Poon LC and Nicolaides KH: Maternal cardiac function at 35-37 weeks' gestation: Prediction of pre-eclampsia and gestational hypertension. Ultrasound Obstet Gynecol 49: 61-66, 2017

19. Tiralongo GM, Lo Presti D, Pisani I, Gagliardi G, Scala RL, Novelli GP, Vasapollo B, Andreoli A and Valensise H: Assessment of total vascular resistance and total body water in normotensive women during the first trimester of pregnancy. A key for the prevention of preeclampsia. Pregnancy Hypertens 5: 193-197, 2015.

20. Adamo KB, Ferraro ZM and Brett KE: Can we modify the intrauterine environment to halt the intergenerational cycle of obesity? Int J Environ Res Public Health 9: 1263-1307, 2012.

21. Siegel AM, Tita AT, Machemehl H, Biggio JR and Harper LM: Evaluation of institute of medicine guidelines for gestational weight gain in women with chronic hypertension. AJP Rep 7: e145-e150, 2017.

22. Demirci O, Kumru P, Arınkan A, Ardıç C, Arısoy R, Tozkır E, Tandoğan B, Ayvacı H and Tuğrul AS: Spot protein/creatinine ratio in preeclampsia as an alternative for 24-hour urine protein. Balkan Med J 32: 51-55, 2015.

23. Stepan H, Kuse-Föhl S, Klockenbusch W, Rath W, Schauf B, Walther T and Schlembach D: Diagnosis and treatment of hypertensive pregnancy disorders. Guideline of DGGG (S1-level, AWMF registry no. 015/018, December 2013). Geburtshilfe Frauenheilkd 75: 900-914, 2015.

24. Kongwattanakul K, Saksiriwuttho P, Chaiyarach S and Thepsuthammarat K: Incidence, characteristics, maternal complications, and perinatal outcomes associated with preeclampsia with severe features and HELLP syndrome. Int J Womens Health 10: 371-377, 2018.

25. Asgharnia M, Mirblouk F, Kazemi S, Pourmarzi D, Mahdipour Keivani $M$ and Dalil Heirati SF: Maternal serum uric acid level and maternal and neonatal complications in preeclamptic women: A cross-sectional study. Int J Reprod Biomed (Yazd) 15: 583-588, 2017.

This work is licensed under a Creative Commons Attribution-NonCommercial-NoDerivatives 4.0 International (CC BY-NC-ND 4.0) License. 